\title{
An Evaluation of Signal Annoyance for a Head-Mounted Tactile Display
}

\author{
by Kimberly Myles and Joel T Kalb
}




\section{NOTICES}

\section{Disclaimers}

The findings in this report are not to be construed as an official Department of the Army position unless so designated by other authorized documents.

Citation of manufacturer's or trade names does not constitute an official endorsement or approval of the use thereof.

Destroy this report when it is no longer needed. Do not return it to the originator. 


\section{Army Research Laboratory}

Aberdeen Proving Ground, MD 21005-5425

ARL-TR-7239

March 2015

\section{An Evaluation of Signal Annoyance for a Head-Mounted Tactile Display}

Kimberly Myles and Joel T Kalb

Human Research and Engineering Directorate, ARL 


\section{REPORT DOCUMENTATION PAGE}

Public reporting burden for this collection of information is estimated to average 1 hour per response, including the time for reviewing instructions, searching existing data sources, gathering and maintaining the data needed, and completing and reviewing the collection information. Send comments regarding this burden estimate or any other aspect of this collection of information, including suggestions for reducing the burden, to Department of Defense, Washington Headquarters Services, Directorate for Information Operations and Reports (0704-0188), 1215 Jefferson Davis Highway, Suite 1204, Arlington, VA 22202-4302. Respondents should be aware that notwithstanding any other provision of law, no person shall be subject to any penalty for failing to comply with a collection of information if it does not display a currently valid OMB control number.

PLEASE DO NOT RETURN YOUR FORM TO THE ABOVE ADDRESS.

\begin{tabular}{|l|l|l|}
\hline 1. REPORT DATE $(D D-M M-Y Y Y Y)$ & 2. REPORT TYPE & 3. DATES COVERED (From - To)
\end{tabular}

\begin{tabular}{l|l} 
March 2015 & Final
\end{tabular}

\section{TITLE AND SUBTITLE}

February 2013-September 2014

An Evaluation of Signal Annoyance for a Head-Mounted Tactile Display

5a. CONTRACT NUMBER

\begin{tabular}{|c|c|}
\hline & 5b. GRANT NUMBER \\
\hline & 5c. PROGRAM ELEMENT NUMBER \\
\hline \multirow[t]{2}{*}{$\begin{array}{l}\text { 6. AUTHOR(S) } \\
\text { Kimberly Myles and Joel T Kalb }\end{array}$} & $\begin{array}{l}\text { 5d. PROJECT NUMBER } \\
\mathrm{H} 70\end{array}$ \\
\hline & $\begin{array}{l}\text { 5e. TASK NUMBER } \\
\text { 5f. WORK UNIT NUMBER }\end{array}$ \\
\hline $\begin{array}{l}\text { 7. PERFORMING ORGANIZATION NAME(S) AND ADDRESS(ES) } \\
\text { US Army Research Laboratory } \\
\text { ATTN: RDRL-HRS-D } \\
\text { Aberdeen Proving Ground, MD 21005-5425 }\end{array}$ & $\begin{array}{l}\text { 8. PERFORMING ORGANIZATION } \\
\text { REPORT NUMBER } \\
\text { ARL-TR-7239 }\end{array}$ \\
\hline \multirow[t]{2}{*}{ 9. SPONSORING/MONITORING AGENCY NAME(S) AND ADDRESS(ES) } & 10. SPONSOR/MONITOR'S ACRONYM(S) \\
\hline & $\begin{array}{l}\text { 11. SPONSOR/MONITOR'S REPORT } \\
\text { NUMBER(S) }\end{array}$ \\
\hline
\end{tabular}

\section{DISTRIBUTION/AVAILABILITY STATEMENT}

Approved for public release; distribution is unlimited.

\section{SUPPLEMENTARY NOTES}

\section{ABSTRACT}

The purpose of this study was to evaluate perceived annoyance for vibrotactile signals applied to the head. A head-mounted tactile display, integrated with a bone conduction system (dual-use, tactile-bone conduction communication system), is considered for military applications, but previous studies have reported unfavorable user reviews for vibrotactile signals applied to the head. Vibrotactile signals from 32 to $250 \mathrm{~Hz}$ were sent to the foreheads of 30 participants who rated the perceived annoyance of each signal. Higher frequency signals were rated more annoying than lower frequency signals. Consequently, higher frequency signals will most likely not be preferred on the head and generally may be associated with annoyance and other feelings of unsettledness. We are not advocating that higher signal frequencies should never be used on the head, because there are times when they may be appropriate, especially for various military applications. However, we must be systematic in how we use them to maintain user acceptance.

\section{SUBJECT TERMS}

tactile, head tactile display, signal frequency, perceived annoyance, user acceptance

\begin{tabular}{|l|l|l|c|c|l|}
\hline \multicolumn{2}{|l|}{$\begin{array}{l}\text { 16. SECURITY CLASSIFICATION OF: } \\
\text { a. REPORT }\end{array}$} & $\begin{array}{c}\text { 17. LIMITATION } \\
\text { OF ABSTRACT }\end{array}$ & $\begin{array}{l}\text { 18. NUMBER } \\
\text { OF PAGES }\end{array}$ & $\begin{array}{l}\text { 19a. NAME OF RESPONSIBLE PERSON } \\
\text { Kimberly Myles }\end{array}$ \\
\cline { 1 - 1 } $\begin{array}{l}\text { Unclassified } \\
\end{array}$ & Unclassified & $\begin{array}{l}\text { C. THIS PAGE } \\
\text { Unclassified }\end{array}$ & UU & 18 & $\begin{array}{l}\text { 19b. TELEPHONE NUMBER (Include area code) } \\
410-278-5998\end{array}$ \\
\hline
\end{tabular}




\section{Contents}

List of Figures $\quad$ iv

$\begin{array}{lr}\text { 1. Introduction } & 1\end{array}$

2. Method 2

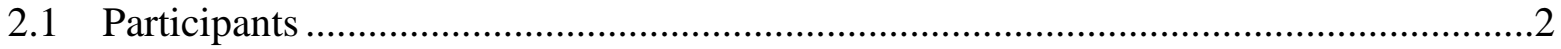

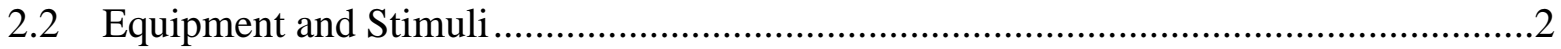

2.3 Experimental Design and Analyses....................................................................

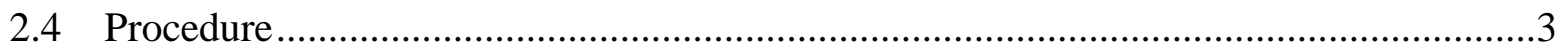

$\begin{array}{lrr}\text { 3. } & \text { Results } & 3\end{array}$

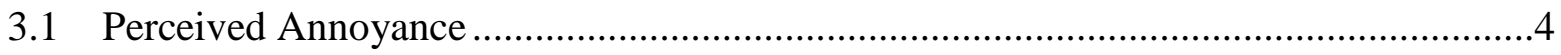

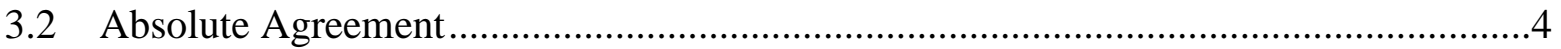

4. Discussion $\quad 5$

$\begin{array}{llr}\text { 5. Conclusions } & 6\end{array}$

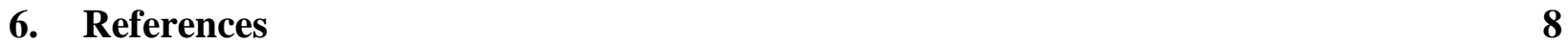

$\begin{array}{ll}\text { Distribution List } & 10\end{array}$ 


\section{List of Figures}

Fig. 1 Mean perceived annoyance by frequency. Error bars represent $95 \%$ confidence interval. Confidence intervals were constructed using the Morey correction for withinsubjects designs. 


\section{Introduction}

A dual-use, tactile-bone conduction (BC) communication system is being considered for military applications. The dual-use system would consist of a traditional BC communication system, which is a microphone and an audio transducer that transmits speech signals to the cochlea via the bony tissue in the skull, but the transducer would also be capable of transmitting vibration to the skin. The BC system would allow Soldiers to effectively communicate in noisy environments while wearing hearing protection, and vibration could be used to convey directional information during periods of high visual workload rather than conveying the information visually. In addition, Soldiers would be able to switch between the 2 systems depending on need. The benefit of transferring information from the visual and auditory sensory channels to the tactile channel is reduced stress on the visual and auditory channels during periods of high workload, which could help to reduce errors and increase situation awareness and performance.

While BC systems are used on or near the head, tactile displays have not been designed to use on the head. Tactile displays have been generally designed to be used on the finger, torso, and arm, and currently, vibrotactile signals are optimized for use on those areas. Thus, integrating BC and tactile technology into one system requires adapting tactile displays for the head. The initial challenge was identifying user-acceptable vibrotactile signals for the head.

Brill and Gilson (2006) reported that participants complained of "dizziness, disorientation, and a general feeling of unsettledness" when exposed to vibrotactile stimulation on the head. They abandoned the head and developed a tactile display for the torso instead. In addition to Brill and Gilson (2006), Hawes and Kumagai (2005) are the only others who have considered a head tactile display for military applications, comparing a head and chest tactile display for infantry navigation. Although a number of subjective ratings for the 2 displays were similar, participants rated the chest tactile display better than the head tactile display. Participants described the vibrations delivered on the head as "too strong" and complained of headaches. The sense of touch is optimal at $250 \mathrm{~Hz}$ (Bolanowski et al. 1988; Lamore and Keemink 1988; van Erp and van den Dobbelsteen 1998), and as a result, current tactile transducers are designed to resonate at this most sensitive frequency when unloaded and provide a uniform displacement frequency response from 25 to $250 \mathrm{~Hz}$ when in contact with the skin. Brill and Gilson (2006) and Hawes and Kumagai (2005) used pulsed tones with 250 and $260 \mathrm{~Hz}$ frequencies, respectively.

Amplitude, frequency, and duration have been identified as important parameters in designing vibrotactile signals. Manipulating one or more of these parameters can influence one's perception of vibrotactile signals. For example, increasing the amplitude (keeping frequency constant) of vibration or increasing the frequency of vibration (keeping amplitude constant) may increase one's perception of the magnitude of the signal (Goff 1967; van Erp 2002; Jones and 
Sarter 2008). Further, a signal of a longer duration may enhance the perception of the signal but may also induce the perception of annoyance (Kaaresoja and Linjama 2005).

van Erp (2002) includes comfort as an important guideline for the design of vibrotactile displays, but very little information is available that addresses the comfort of vibrotactile signals. In general, van Erp (2002) states that a high-intensity vibrotactile signal may lead to discomfort and pain and that comfort may be achievable at 15 to $20 \mathrm{~dB}$ above absolute threshold. However, this has yet to be established for the head. For this reason, it is worthwhile to identify tolerable and comfortable vibrotactile signals for the head to develop and advance head tactile displays. Thus, the purpose of this study was to evaluate perceived annoyance (as a function of vibration frequency) for vibrotactile signals applied to the head.

\section{Method}

\subsection{Participants}

Thirty participants (29 males and 1 female), with little to no hair on the head, were recruited from the central Maryland area. They provided informed consent and were paid for participation in this study. The age range of participants was 18 to 37 years $(M=25.53, S D=5.6)$. The protocol to conduct this study was approved by the US Army Research Laboratory Institutional Review Board.

\subsection{Equipment and Stimuli}

An elastic headband held one tactile transducer $(3.05 \mathrm{~cm}$ in diameter by $0.79 \mathrm{~cm}$ in height; weight of 17 grams) at the forehead of participants. The transducer was a commercial-off-theshelf product of the EAI Corporation. Vibrotactile signals, with frequency ranging from 32 to $250 \mathrm{~Hz}$, were amplitude-modulated with a series of three $250 \mathrm{~ms}$ pulses, each with a $25 \%$ duty cycle, and tapered, rising, and falling edges to minimize transient artifacts. Signals produced at the output of the computer were sent to an external circuit board for power amplification. Amplitude was held constant at $2.22 \mathrm{~V}$ peak - a limitation of the equipment.

Standard one-third octave frequency tactile signals were used for this study $(32,50,63,80$, $100,125,150,200$, and $250 \mathrm{~Hz}$ ). In addition, 2 one-twelfth octave frequency signals (45 and $160 \mathrm{~Hz}$ ) were included and motivated by 2 of our previous studies regarding the audible frequency discrimination of vibrotactile signals and the detection and localization of vibrotactile signals while walking and running. This range will help to define a database of vibrotactile signals that users perceive as acceptable on the head. 


\subsection{Experimental Design and Analyses}

A one-way, within-subjects design was used to evaluate subjective annoyance ratings for 11 vibratory tactile signals. Signal frequency $(32,45,50,63,80,100,125,150,160,200$, and $250 \mathrm{~Hz}$ ) was the within-subject variable. The presentation order of frequency was randomized. The dependent variable was perceived annoyance, which was obtained via a 5-point Likert scale. A one-way, within-subjects analysis of variance (ANOVA) was used to compare the differences in perceived annoyance ratings due to signal frequency, using $\alpha=0.05$. Post hoc-paired comparisons were evaluated using Tukey's HSD (honestly significant difference) test. We also analyzed absolute agreement between the participants' individual annoyance ratings.

We assigned each of the 11 signal frequencies to 1 of 3 more meaningful frequency categories that indicated the magnitude of signal frequency: low $(32-63 \mathrm{~Hz})$, medium $(80-150 \mathrm{~Hz})$ and high $(160-250 \mathrm{~Hz})$. Frequency ranges were assigned based on earlier pilot studies that examined user tolerances to vibratory signals when applied to the head. A one-way, within-subjects ANOVA was used to compare the differences in perceived annoyance ratings due to the categories of signal frequencies, using $\alpha=0.05$.

\subsection{Procedure}

Each participant gave informed consent prior to the study. Participants donned an elastic headband that held one tactile transducer at the forehead. Participants were then seated in an indoor laboratory and exposed, via the transducer on the forehead, to one random series of all 11 vibratory signals. During this initial presentation of the signals, participants did not provide ratings of annoyance. They were told to use the first presentation of the signals to familiarize themselves with each signal relative to all the other signals.

Participants were then exposed to a second random series of the 11 vibratory signals and rated each signal for its level of annoyance relative to all the other signals. After each signal was presented, an electronic version of a Likert scale followed, and participants rated the signal 1 (not annoying at all) to 5 (very annoying). After participants clicked the appropriate radio button to register an annoyance rating, the next signal was presented until all 11 signals were rated.

\section{Results}

There is current debate regarding the use of parametric procedures to analyze subjective rating scale measurements (Knapp 1990; Jamieson 2004; Norman 2010). Aware of both arguments, we initially used both parametric and nonparametric statistical procedures to analyze perceived annoyance and obtained comparable results. Thus, we report perceived annoyance results using parametric statistical procedures. 


\subsection{Perceived Annoyance}

Mauchly's test indicated that the assumption of sphericity was violated, $\chi^{2}(54)=112.85$, $p<0.001$, therefore the degrees of freedom were corrected using Greenhouse-Geisser estimates of sphericity $(\varepsilon=0.51)$. The results showed that the effect of frequency on perceived annoyance was significant, $F(5.08,147.18)=43.11, p<0.001, \eta^{2}=0.60$ (Fig. 1).

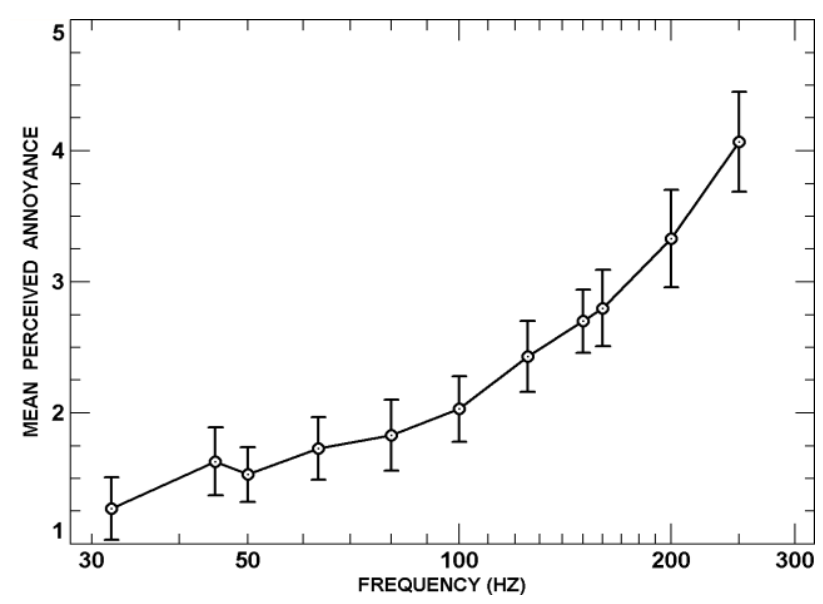

Fig. 1 Mean perceived annoyance by frequency. Error bars represent $95 \%$ confidence interval. Confidence intervals were constructed using the Morey (2008) correction for withinsubjects designs.

Mean perceived annoyance for the low-, medium-, and high-frequency groups were 1.54, 2.25, and 3.4, respectively. Annoyance ratings were significantly different across frequency groups, $F(1.39,40.41)=136.09, p<0.001, \eta^{2}=.82$, and the degrees of freedom were corrected using Greenhouse-Geisser estimates of sphericity $(\varepsilon=.70)$, a consequence of a Mauchly's test sphericity violation, $\chi^{2}(2)=16.00, p<0.001$. Paired comparisons showed that each frequency group differed from all the other frequency groups. Vibratory signals in the high-frequency group were rated as more annoying than signals in the low-frequency group, $p<0.05$. Signals in the medium-frequency group were rated more annoying than signals in the low-frequency group, $p<0.05$ but less annoying than signals in the high-frequency group, $p<0.05$.

\subsection{Absolute Agreement}

Following guidance from Shrout and Fleiss (1979), we used a 2-way random-effects intraclass correlation coefficient analysis to evaluate the magnitude of agreement between all participants' annoyance ratings. We found $46 \%$ agreement between the ratings, which indicates that participants were in moderate agreement regarding the annoyance of the vibrotactile signals at the different levels of frequency. 


\section{Discussion}

The purpose of this research was to evaluate the perceived annoyance of vibrotactile signals when applied to the head. We obtained annoyance ratings for vibrotactile signals of varying frequencies $(32-250 \mathrm{~Hz})$. Participants rated the $32-\mathrm{Hz}$ signal as least annoying and the $250-\mathrm{Hz}$ signal as most annoying. Significant differences in frequency revealed that signals with frequencies less than or approximately equal to $63 \mathrm{~Hz}$ were found to be significantly less annoying than signals greater than or approximately equal to $160 \mathrm{~Hz}$. Furthermore, the highest levels of annoyance were observed at 200 and $250 \mathrm{~Hz}$.

A linear relationship between perceived annoyance and signal frequency also emerged, revealing a general increase in perceived annoyance with an increase in signal frequency. These findings support Brill and Gilson (2006) and Hawes and Kumagai (2005), who reported that headaches and feelings of unsettledness, disorientation, and dizziness are associated with tactile stimulation of the head, as both used signal frequencies where we observed the highest levels of annoyance. Of the 19 annoyance ratings recorded at the maximum end of the rating scale (5), 79\% of those ratings were assigned to the $250-\mathrm{Hz}$ signal. These results may suggest that some, but not all, vibrotactile signals might produce too much energy on the head. Although it is possible that ratings could be rated less annoying after several exposures to the signals because of adaptation and habituation, it is not certain that this would be the case for the highest frequency vibrotactile signals, 200 and $250 \mathrm{~Hz}$.

Because the mean difference in annoyance ratings was higher between the medium-to-highfrequency groups than between the medium-to-low-frequency groups, this may suggest that participants in this study are more like-minded in their perception of annoyance regarding vibrotactile signals with lower frequencies. This may even be true for the few signal frequencies in the medium range positioned closer to the low-frequency border. Thus, participants likely perceived that lower frequency signals were not annoying. However, the shared perceptual map for annoyance appeared to take on more variability as the signal frequency increased. The increased variability may suggest differences in the perception of annoyance. It may also suggest differences in each participant's criterion in establishing a reference frequency along the medium-to-high-frequency range to separate the less-annoying signals from the most-annoying signals. The latter may be responsible for the moderate agreement observed between the participant's individual annoyance ratings.

While moderate agreement regarding perceived annoyance may be attributed to individual criterion for judging vibration annoyance on the head, it may also be attributed to the methodology we used to assess annoyance. We initially presented one random series of all 11 vibratory signals. During this initial presentation of the signals, the participants did not provide ratings of annoyance; they only familiarized themselves with each signal relative to all 
the other signals. We then presented participants with a second random series of the 11 signals in which participants provided an annoyance rating after each signal was presented. Participants were instructed to rate each signal relative to all the other signals. It is possible that we would observe an increase in agreement between ratings by limiting relative comparisons to 2 signal frequencies via the 2-alternative forced-choice paradigm. Moderate agreement may also suggest that there is a better construct, or an additional construct, to evaluate users' acceptance of vibratory signals on the head.

The effect of frequency on perceived annoyance was moderately large and suggests that participants were able to delineate differences in signal frequency along the construct of annoyance. Holding subjective intensity constant, Goff (1967) reported that sensitivity to changes in signal frequency is relatively good below $100 \mathrm{~Hz}$ and thus frequency is an adequate parameter for coded communication on the skin for this frequency range. Goff (1967) also advocates pairing frequency with intensity and duration, which Pratt et al. (2012) demonstrate can influence one's perception of perceived urgency. Their results showed that perceived urgency increased as the stimulus pulse rate increased, but they also found that the level of annoyance may also increase.

\section{Conclusions}

Vibrotactile signals that will be used on the head should not be annoying. Based on the results of this study, higher frequency signals (for which the sense of touch has been identified as optimum for other body sites) will most likely not be preferred on the head by most users, and generally, may be associated with annoyance and other feelings of unsettledness. We are not advocating that higher signal frequencies should never be used on the head because there are times when they may be appropriate, especially for various military applications. However, we must be systematic in how we use them to maintain user acceptance. To do so will make head tactile displays more appealing to the user. Of course, other vibrotactile signal parameters are important in assessing perception and perceived annoyance, and future research should include assessing annoyance using these signal parameters, such as amplitude and duration. This is especially critical when conducting laboratory and field research to assess the efficacy of head tactile displays for military applications.

Most commercially available tactile displays that are designed for use on other body sites usually provide the user with options, although limited, for manipulating signal intensity, but seldom provide the option for varying the frequency. This is an indication that one or a few standard signal frequencies are chosen for system design. Thus, when designing head tactile displays using this paradigm, standard signal frequencies for the display should meet mission goals and align with what users' judge as acceptable. 
User approval will be crucial to the development and advancement of head tactile displays. The development of head tactile displays will be curtailed if the user cannot tolerate the vibrotactile signals that are designed to communicate specific information or phenomena. The challenge will be to identify a range of optimal signals for all users that can be used in many environments, and under a number of conditions. 


\section{References}

Bolanowski SJ, Gescheider GA, Verillo RT, Chechosky CM. Four channels mediate the mechanical aspects of touch. Journal of the Acoustical Society of America. 1988;84(5):1680-1694.

Brill JC, Gilson RD. Tactile technology for covert communications. Proceedings of the Human Factors and Ergonomics Society 50th Annual Meeting; 2006 Oct 16-20; San Francisco, CA. Thousand Oaks (CA): SAGE Publications; 2006;50(16):1692-1696.

Goff G. Differential discrimination of frequency of cutaneous mechanical vibration. Journal of Experimental Psychology. 1967;74:294-299.

Hawes VL, Kumagai JK. Examination of head and chest located tactile information for infantry wayfinding. Toronto (Canada): Defence Research and Development Canada. 2005. Report No.: DRDC-TORONTO-CR-2005-042.

Jamieson S. Likert scales: how to (ab)use them. Medical Education. 2004;38:1212-1218.

Jones LA, Sarter NB. Tactile displays: guidance for their design and application. Human Factors. 2008;50(1):90-111.

Kaaresoja T, Linjama J. Perception of short tactile pulses generated by a vibration motor in a mobile phone. Proceedings of the First Joint Eurohaptics Conference and Symposium on Haptic Interfaces for Virtual Environment and Teleoperator Systems; 2005 Mar 18-20; Pisa, Italy; Los Alamitos (CA): IEEE Computer Society; 2005:471-472.

Knapp TR. Treating ordinal scales as interval scales: an attempt to resolve the controversy. Nursing Research. 1990;39(2):121-123.

Lamore PJJ, Keemink CJ. Evidence for different types of mechanoreceptors from measurements of the psychophysical threshold for vibrations under different stimulation conditions. Journal of the Acoustical Society of America. 1988;83(6):2339-2351.

Morey RD. Confidence intervals from normalized data: a correction to Cousineau (2005).

Tutorial in Quantitative Methods for Psychology. 2008;4(2):61-64.

Norman G. Likert scales, levels of measurement and the "laws" of statistics. Advances in Health Sciences Education. 2010;15:625-632.

Pratt SM, Lewis BA, Penaranda BN, Roberts DM, Gonzalez C, Baldwin CL. Perceived urgency scaling in tactile alerts. Proceedings of the Human Factors and Ergonomics Society 56th Annual Meeting; 2012 Oct 22-26; Boston, MA; Thousand Oaks (CA): SAGE Publications; 2012;56(1):1303-1306. 
Shrout PE, Fleiss JL. Intraclass correlations: uses in assessing rater reliability. Psychological Bulletin. 1979;86(2):420-428.

van Erp JBF. Guidelines for the use of vibro-tactile displays in human computer interaction. In: Wall SA, Riedel B, Crossan A, McGee MR, editors. Proceedings of Eurohaptics. 2002 Jul 8-10; Edingburgh, UK. 2002;18-22.

van Erp JBF, van den Dobbelsteen JJ. On the design of tactile displays. Soesterberg (The Netherlands): TNO Human Factors Research Institute. 1998. Report No.: TM-98-B012. 


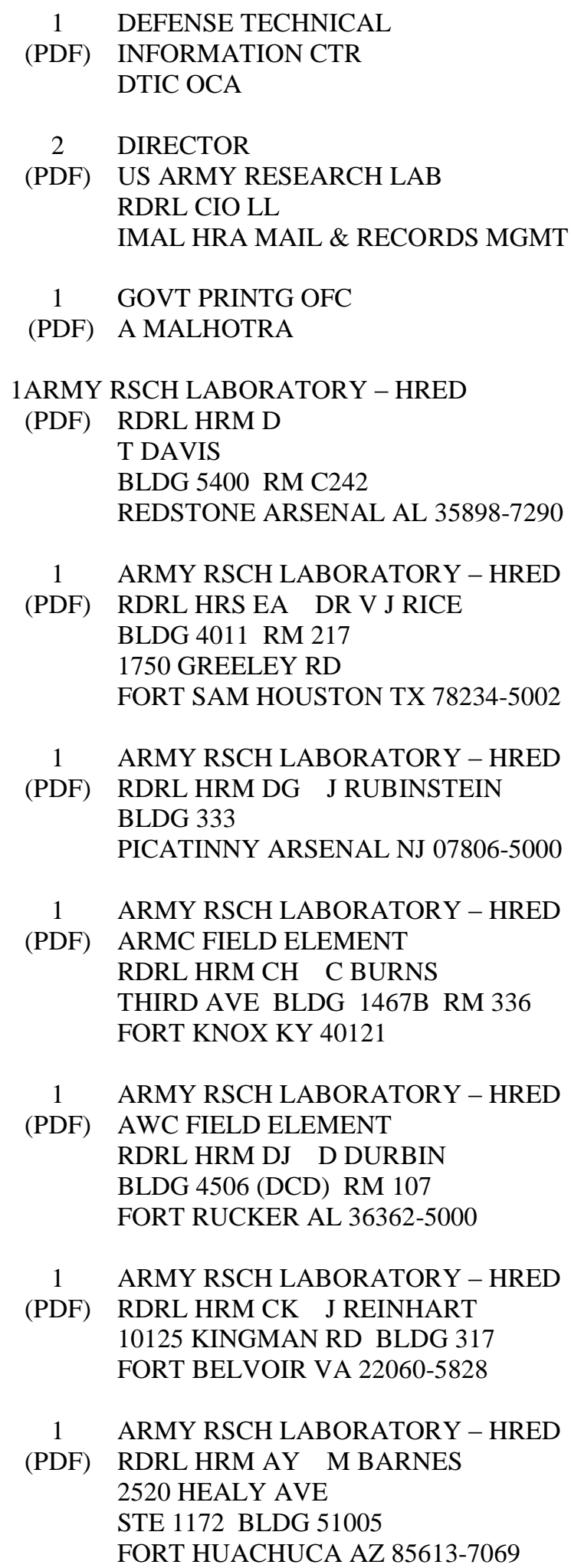

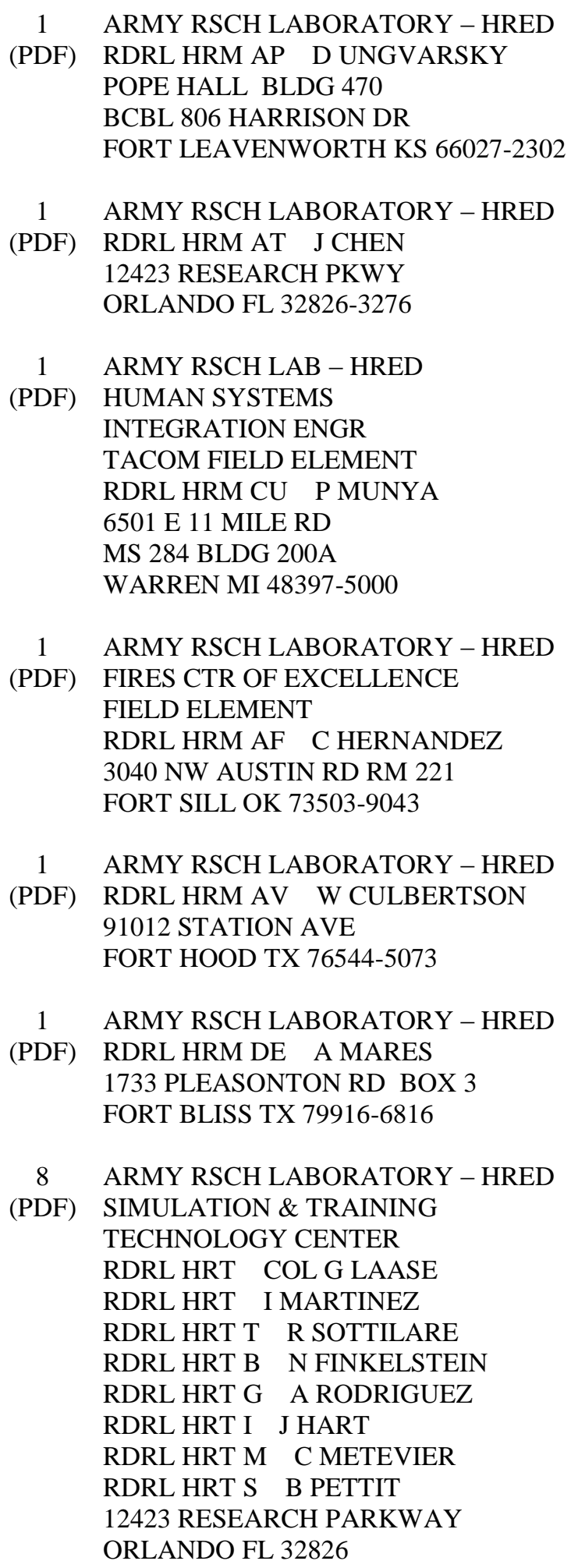




$\begin{array}{cl}11 & \text { ARMY RSCH LABORATORY - HRED } \\ \text { (PDF) } & \text { HQ USASOC } \\ & \text { RDRL HRM CN R SPENCER } \\ & \text { BLDG E2929 DESERT STORM DRIVE } \\ & \text { FORT BRAGG NC 28310 } \\ 1 & \text { ARMY G1 } \\ \text { (PDF) } & \text { DAPE MR B KNAPP } \\ & \text { 300 ARMY PENTAGON RM 2C489 } \\ & \text { WASHINGTON DC 20310-0300 } \\ & \\ \text { ABERDEEN PROVING GROUND } \\ \text { 12 } \\ \text { DIR USARL } \\ \text { RDRL HR } \\ \text { L ALLENDER } \\ \text { P FRANASZCZUK } \\ \text { K MCDOWELL } \\ \text { RDRL HRM } \\ \text { P SAVAGE-KNEPSHIELD } \\ \text { RDRL HRM AL } \\ \text { C PAULILLO } \\ \text { RDRL HRM B } \\ \text { J GRYNOVICKI } \\ \text { RDRL HRM C } \\ \text { L GARRETT } \\ \text { RDRL HRS } \\ \text { J LOCKETT } \\ \text { RDRL HRS B } \\ \text { M LAFIANDRA } \\ \text { RDRL HRS D } \\ \text { K MYLES } \\ \text { A SCHARINE } \\ \text { RDRL HRS E } \\ \text { D HEADLEY } \\ \end{array}$


INTENTIONALLY LEFT BLANK. 